\title{
Synthesis, Characterization, and Thermal Decomposition of Pure and Dysprosium Doped Yttrium Phosphate System
}

\author{
K. K. Bamzai, Nidhi Kachroo, Vishal Singh, and Seema Verma \\ Crystal Growth and Material Research Laboratory, Department of Physics \& Electronics, University of Jammu, Jammu 180006, India \\ Correspondence should be addressed to K. K. Bamzai; kkbamz@yahoo.com
}

Received 30 December 2012; Revised 21 March 2013; Accepted 21 March 2013

Academic Editor: Rodrigo Martins

Copyright ( $) 2013$ K. K. Bamzai et al. This is an open access article distributed under the Creative Commons Attribution License, which permits unrestricted use, distribution, and reproduction in any medium, provided the original work is properly cited.

\begin{abstract}
Yttrium phosphate and dysprosium doped yttrium phosphate were synthesized from aqueous solutions using rare earth chloride, phosphoric acid, and traces of ammonium hydroxide. The synthesized material was then characterized for their structural investigations using powder X-ray diffraction (XRD) analysis and scanning electron microscopy (SEM) supplemented with energy dispersive X-ray analysis (EDAX). The spectroscopic investigations were carried out using Fourier transform infrared (FTIR) spectroscopy. The thermal stability was studied using differential thermogravimetric analysis (DTA), thermogravimetric analysis (TGA), and differential scanning calorimetry (DSC) techniques. X-ray diffraction analysis reveals that both yttrium phosphate and dysprosium doped yttrium phosphate belong to tetragonal system with lattice parameter $a=b=6.8832 \AA, c=6.0208$ $\AA$ and $a=b=6.9987 \AA, c=6.0142 \AA$, respectively. The stoichiometry of the grown composition was established by energy dispersive X-ray analysis. The EDAX analysis suggests the presence of water molecules. The presence of water molecules along with orthophosphate group and metallic ion group was confirmed by FTIR analysis. Thermogravimetric analysis suggests that decomposition in case of yttrium phosphate takes place in three different stages and the final product stabilizes after $706^{\circ} \mathrm{C}$, whereas in case of dysprosium doped yttrium phosphate the decomposition occurs in two different stages, and the final product stabilizes after $519^{\circ} \mathrm{C}$.
\end{abstract}

\section{Introduction}

Rare earth phosphates belong to the family of rare earth zircons. The crystal of rare earth phosphate crystallizes into tetragonal zircon structure. The general formula for rare earth zircon is $\mathrm{RXO}_{4}$, where " $\mathrm{R}$ " = rare earth and " $\mathrm{X}$ " = P, $\mathrm{V}$, or As. Here each "X" atom is surrounded by an oxygen tetrahedron, and each rare earth atom surrounded by eight nearest neighbor oxygen atoms [1]. The rare earth ions $\left(\mathrm{R}^{3+}\right)$ and phosphorous $\left(\mathrm{P}^{5+}\right)$ ions occupy sites of tetragonal symmetry. There are four molecules per unit cell. Rare earth phosphates find their place in wide variety of applications such as optical materials including lasers [2], phosphors [3], and more recently as anti-UV materials [4]. Rare earth orthophosphates exhibit certain properties that make them of interest as scintillators for gamma-ray detection [5-7], as thermophosphors for remote measurement of temperature on moving components [8], and as rare earth analytical standards [9]. Rare earth codoping in inorganic materials has a long held transition of facilitating highly desirable optoelectronic properties for their potential applications to the laser industry. Rare earth compounds were extensively applied in luminescent and display, such as lighting, field emission display (FED), cathode ray tubes (CRT), and plasma display panel (PDP) [10-12].

Amorphous rare earth phosphates were synthesized by precipitation method [13]. Guo et al. [14] had reported the sol-gel synthesis of $\mathrm{RePO}_{4}(\mathrm{Re}=\mathrm{La}, \mathrm{Ce}, \mathrm{Nd}, \mathrm{Eu}, \mathrm{Y})$. Synthesis of rare earth phosphates by wet precipitation method has been reported by different research groups [1517]. Nedelec et al. [18] reported the dependence of optical properties on the synthesis of $\mathrm{YPO}_{4}$, whereas the thermal decomposition of $\mathrm{RePO}_{4} \cdot n \mathrm{H}_{2} \mathrm{O}(\mathrm{Re}=\mathrm{La}, \mathrm{Ce}, \mathrm{Y})$ was reported by Lucas et al. [19]. Several other authors reported the synthesis of rare earth phosphate compounds by different methods such as high temperature solid state reaction technique, wet chemical precipitation technique, and sol-gel and hydrothermal synthesis [20-24]. The physicochemical 
properties of the material, which depends on the synthesis route, that is, chemical composition, grain size, morphology, and the crystalline structure, influence the thermal behavior the end product, and therefore their final physicochemical properties. So these factors are of prime importance in the manufacturing processes. There is no study concerning pure and doped yttrium phosphate through the influence synthesis parameters on the characteristics of the resulting material. This paper, therefore, deals with study of yttrium phosphate and dysprosium doped yttrium phosphate grown by an aqueous solution method using constituent material like yttrium chloride, dysprosium chloride, phosphoric acid, and traces of ammonium hydroxide. To the best of author's knowledge no such detailed work on the synthesis by this method, characterization, and thermal behavior was reported.

\section{Materials and Methods}

2.1. Materials Preparation. Yttrium phosphate $\left(\mathrm{YPO}_{4}\right)$ hereafter abbreviated as (YP) was grown by reacting phosphoric acid $\left(\mathrm{H}_{3} \mathrm{PO}_{4}\right)$ with rare earth chlorides $\left(\mathrm{RCl}_{3}, \mathrm{R}=\mathrm{Y}\right)$ using ammonia solution $\left(\mathrm{NH}_{4} \mathrm{OH}\right)$ to adjust the $\mathrm{pH}$. The chemical used in the present study are: yttrium chloride $\left(\mathrm{YCl}_{3}\right)$ and dysprosium chloride $\left(\mathrm{DyCl}_{3}\right)$ (Indian Rare Earth Ltd. 99\%); phosphoric acid $\left(\mathrm{H}_{3} \mathrm{PO}_{4}\right)$ and ammonia solution $\left(\mathrm{NH}_{4} \mathrm{OH}\right)$ (AR grade from S.D.Fine Chemicals). Many researchers have given this technique the name of precipitation method [25] or sol-gel synthesis [14]. However, it is worth noticeable that in all the reported works the synthesized material was later sintered at high temperatures to obtain the crystalline form, whereas in the present work no such sintering or heating of the material was done. In case of YP the material was obtained in the form of crystals at the room temperature, whereas in case of dysprosium doped yttrium phosphate instead of crystals floral shaped growth it was obtained over the condensed gel.

An aqueous solution of $0.5 \mathrm{M}$ of yttrium chloride was mixed with an aqueous solution of $0.5 \mathrm{M}$ of phosphoric acid in the ratio of $1: 5$. Then ammonia solution was added to the mixture drop by drop until a $\mathrm{pH}$ of 3 was obtained amid continuous stirring. The solution was then put into the crystallizing dish, then kept undisturbed in the constant temperature bath at ambient temperature $\left(35-40^{\circ} \mathrm{C}\right)$. After two weeks, the solvent was evaporated from the crystallizing dish, condensed gel was obtained and cracks were seen on the surface of condensed gel after a few days, and then small size crystals appeared. After the period of 30 days, crystals were taken out and washed under running water. The chemical reaction that took place in the previous process is as follows:

$$
\begin{aligned}
\mathrm{YCl}_{3} & +\mathrm{H}_{3} \mathrm{PO}_{4}+\mathrm{NH}_{4} \mathrm{OH} \\
& \longrightarrow \mathrm{YPO}_{4}+3 \mathrm{HCl}+\mathrm{NH}_{3}+\mathrm{H}_{2} \mathrm{O} .
\end{aligned}
$$

The preparation of $2 \%$ dysprosium doped yttrium phosphate $\left(\mathrm{Dy}_{0.02} \mathrm{Y}_{0.98} \mathrm{PO}_{4}\right)$ here after abbreviated as (DyYP) was also based on the same procedure. The solution of yttrium and dysprosium was made in such a way that the only traces of dysprosium nearly $2 \%$ appear in the material. An aqueous solution of $0.5 \mathrm{M}$ of yttrium chloride and dysprosium chloride was mixed with an aqueous solution of $0.5 \mathrm{M}$ of phosphoric acid in the ratio of $1: 5$. Then ammonia solution was added to the mixture drop by drop until a $\mathrm{pH}$ of 3 was obtained amid continuous stirring. The solution was then kept undisturbed in the constant temperature bath at ambient temperature $\left(35^{\circ}-40^{\circ} \mathrm{C}\right)$. During the period of 40 days, the material in the crystallizer condensed into a gel-like substance and became hard, and after few days, the gel broke into pieces and small flower-like growth appeared over each piece of the condensed gel. The chemical reaction that took place in the previous process is as follows:

$$
\begin{aligned}
& \mathrm{Dy}_{0.02} \mathrm{Y}_{0.98} \mathrm{Cl}_{3}+\mathrm{H}_{3} \mathrm{PO}_{4}+\mathrm{NH}_{4} \mathrm{OH} \\
& \longrightarrow \mathrm{Dy}_{0.02} \mathrm{Y}_{0.98} \mathrm{PO}_{4}+3 \mathrm{HCl}+\mathrm{NH}_{3}+\mathrm{H}_{2} \mathrm{O} .
\end{aligned}
$$

2.2. Characterization. The characterization techniques consisted of X-ray diffraction (XRD), scanning electron microscopy (SEM) supplemented with energy dispersive $\mathrm{X}$ ray analysis (EDAX), Fourier transform infrared spectroscopy (FTIR), thermogravimetry (TGA), differential thermogravimetry (DTA), and differential scanning calorimetry (DSC). Powder X-ray diffraction was performed using Rich Seifert powder X-ray diffractometer (model ISO Debye Flux 2002). Scanning electron microscope model numberJSM6100 supplemented with energy dispersive X-ray analysis was used to study morphology and elemental composition of the grown crystals. To study the presence of phosphate and other groups in the crystals Fourier transform infrared (FTIR) spectrum was obtained on Perkin-Elmer 781 spectrophotometer in the regions from 400 to $4000 \mathrm{~cm}^{-1}$ using $\mathrm{KBr}$ pellet. TGA and DTA curves were recorded simultaneously on the thermal analyzer (Shimadzu make DTG-60) over the temperature range from 25 to $1000^{\circ} \mathrm{C}$ at the heating rate of $10^{\circ} \mathrm{C} / \mathrm{min}$ in the $\mathrm{N}_{2}$ atmosphere at a flow rate of $30 \mathrm{~mL} / \mathrm{min}$.

\section{Results and Discussion}

3.1. Optical Microscopy. Optical microscopy was involved for rapid scanning of the grown crystals. Photomicrograph of YP and DyYP is shown in Figures 1(a) and 1(b), respectively. Yttrium phosphate appears transparent as well as platelet in nature, whereas DyYP shows clear view of the flower-like arrangement.

3.2. Scanning Electron Microscopy (SEM). Electron microscopy is a powerful tool to investigate the microstructure of single crystal. Figure 2 shows the SEM image of YP crystal. From the image, it is clear that it is a platelet-like crystal with clear and smooth surfaces. However, DyYP grew in the form of floral growth over the condensed gel. These floral growths were then scanned to have a closer look on the morphology of the material. Figure 3 gives a clear picture of the SEM image of DyYP. From the image, it is seen that the material has grown in such a way that there are striations all over the grown area. Striations are caused by a crystal alternating between crystal faces, as it grows. Striations are generally classified as positive and negative types. Striations, parallel to the crystal 


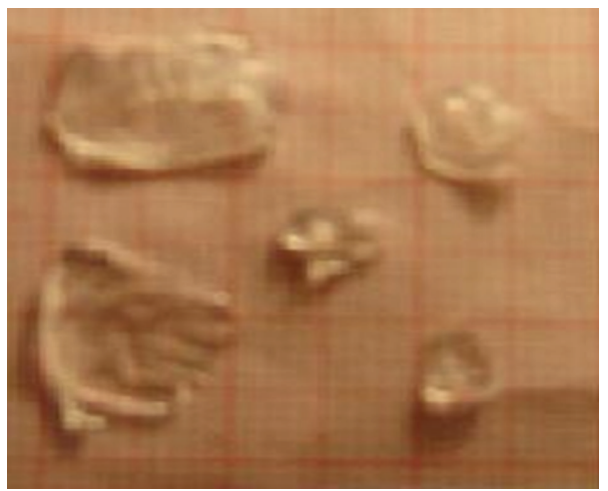

(a)

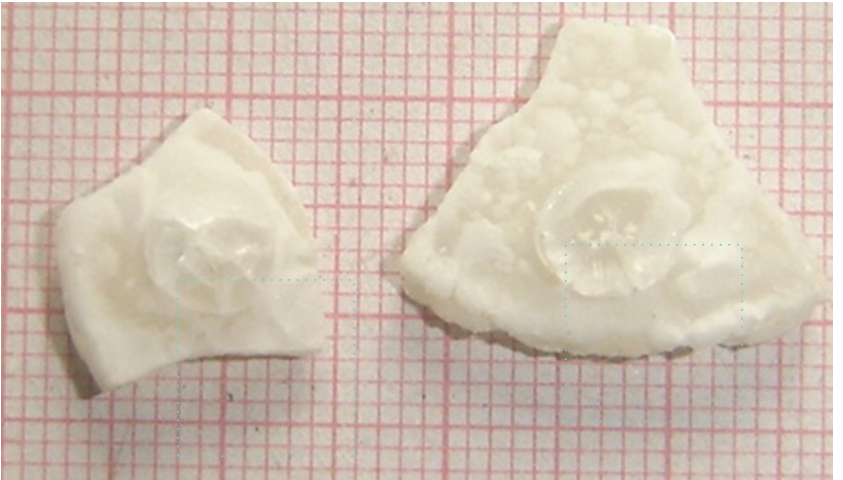

(b)

FIgURE 1: Photomicrograph as seen under optical microscope for (a) yttrium phosphate crystals; (b) dysprosium doped yttrium phosphate.

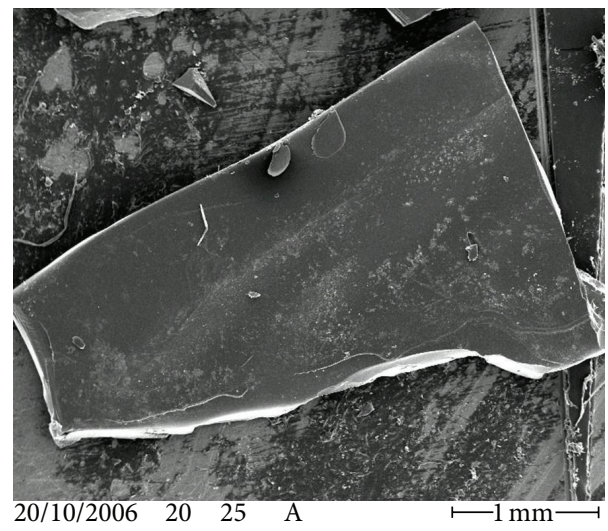

FIGURE 2: Scanning electron micrograph of pure YP crystal which clearly shows the platelet morphology of the crystal.

faces are called positive striations and those perpendiculars to the growth faces are called negative striations [26]. In the present case, since the striations were parallel to the growth surface, they are suggested to be positive striations. Temperature fluctuations are often regarded as the root cause of all types of striations [27].

3.3. X-Ray Diffraction Analysis (XRD). Figure 4(a) shows the XRD graph of YP crystal. The graph consists of high resolved peaks at some specific $2 \theta$ Bragg's angles depicting the crystalline nature of the material. The data was compared with JCPDS data number 84-0335 which suggest that crystal belongs to tetragonal system. The cell parameters were found to be $a=b=6.8832 \AA, c=6.0208 \AA$. The unit cell volume as calculated by WINPLOTR software comes out to be 285.3 cubic A. Figure 4(b) shows the diffraction pattern of the DyYP crystal. From the graph, it is clear that like YP, DyYP also has a well-versed crystallinity. The lattice parameters for DyYP comes out to be $a=b=6.9987 \AA, c=6.0142 \AA$. The unit cell volume came out to be 294.6 cubic $\AA$.

3.4. Energy Dispersive X-Ray Analysis (EDAX). To study the elemental composition of YP and DyYP, qualitative and

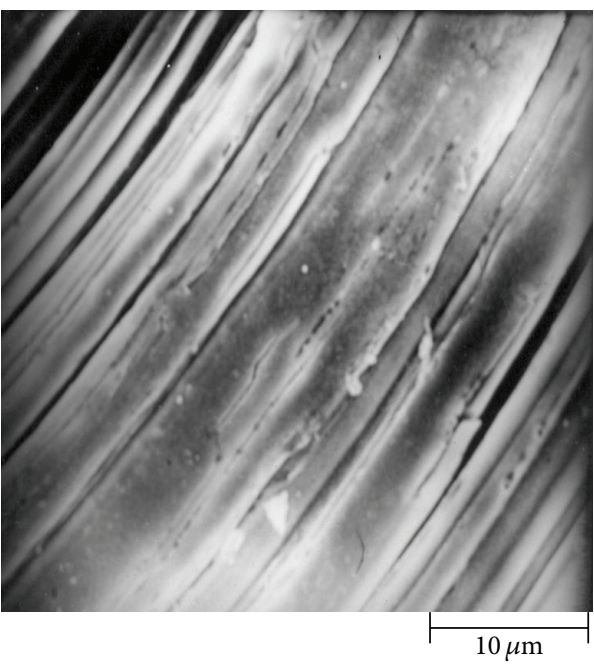

FIgURE 3: Scanning electron micrograph of floral part of DyYP revealed certain kind of striations at the surface of the grown material.

quantitative analysis were performed by energy dispersive Xray analysis. The spectrum obtained from EDAX analyses is shown in Figures 5(a) and 5(b). EDAX pattern shows peaks corresponding to all the major elements present in the grown crystals as should be expected from YP system. The spectra corresponding to doped DyYP shows peaks corresponding to all the major elements, that is, yttrium, phosphorous, and oxygen along with dysprosiumby suggesting that Dy has entered into the lattice of YP system. However, along with these elements some trace impurities in the form of chlorine and nitrogen were observed. The experimental and theoretical calculated atomic and weight percentages of elements in YP and DyYP is given in Tables 1(a) and 1(b), respectively. For YP crystals the theoretical values were calculated as per the formula $\mathrm{YPO}_{4} \cdot \mathrm{H}_{2} \mathrm{O}$, whereas for DyYP system the values were calculated as per the formula $\mathrm{Dy}_{0.02} \mathrm{Y}_{0.98} \mathrm{PO}_{4} \cdot 2 \mathrm{H}_{2} \mathrm{O}$. However, it is important to mention here that EDAX analysis does not give experimental values of atomic and weight percentage for lighter elements like hydrogen. Therefore, in 


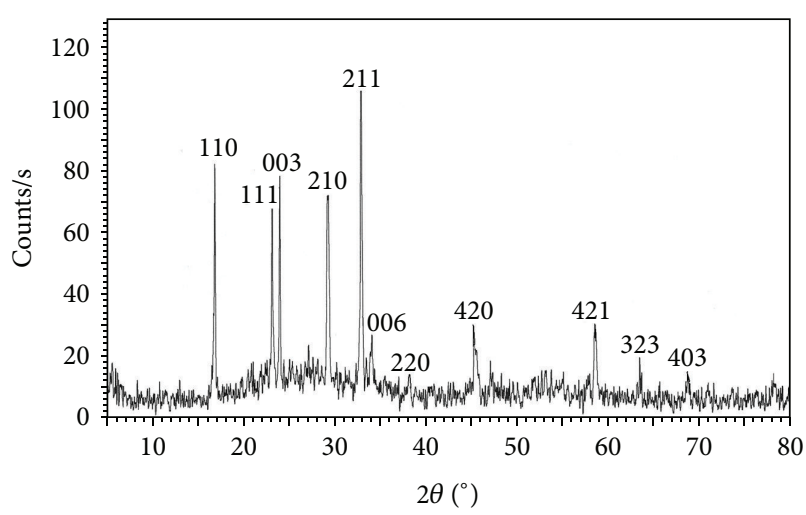

(a)

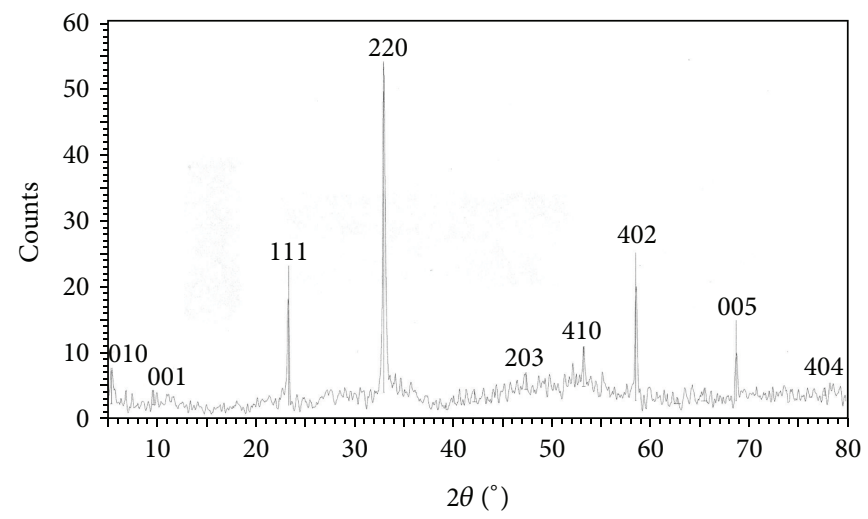

(b)

FIGURE 4: XRD diffractograms which clearly depict the presence of crystallinity in the material, along with indexing of all the prominent peaks for (a) yttrium phosphate (YP); (b) dysprosium doped yttrium phosphate (DyYP).

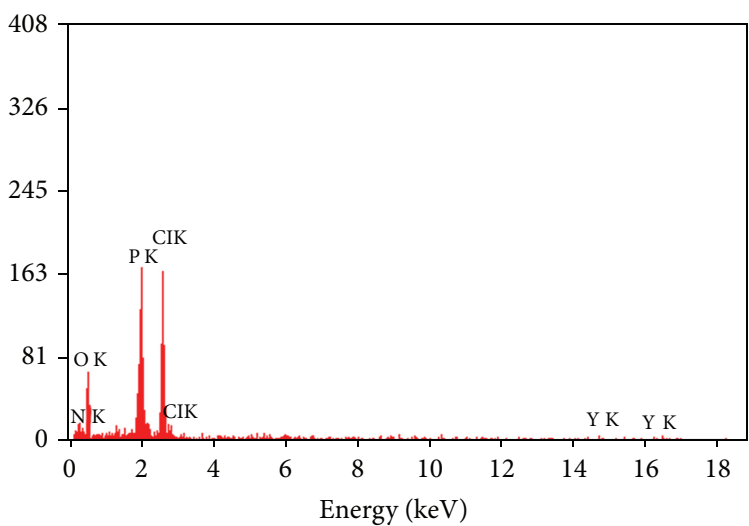

(a)

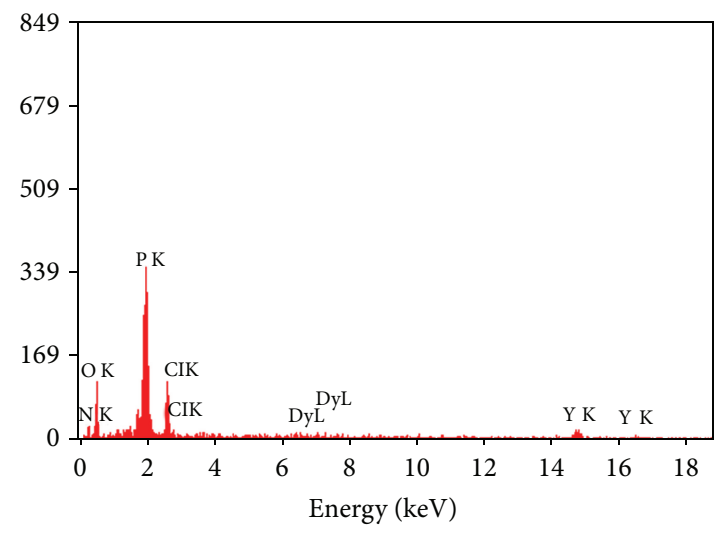

(b)

FIGURE 5: EDAX spectra showing the presence of suggested elements along with some impurity elements for (a) Yttrium phosphate (YP); (b) Dysprosium doped yttrium phosphate (DyYP).

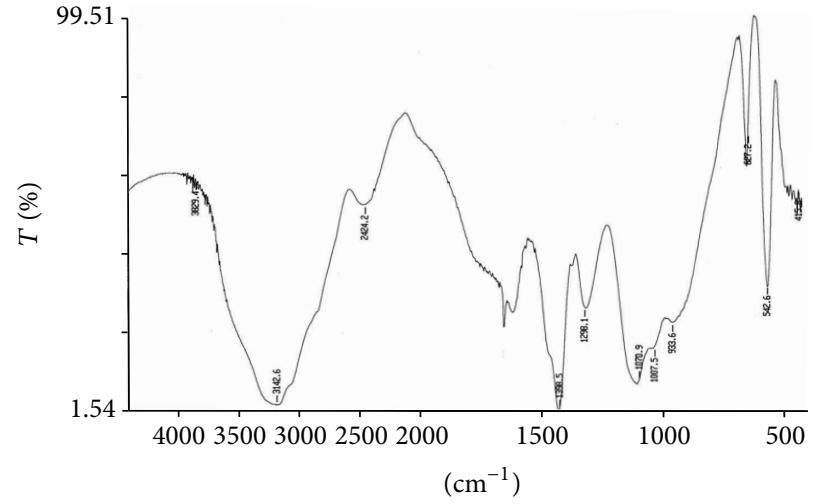

(a)

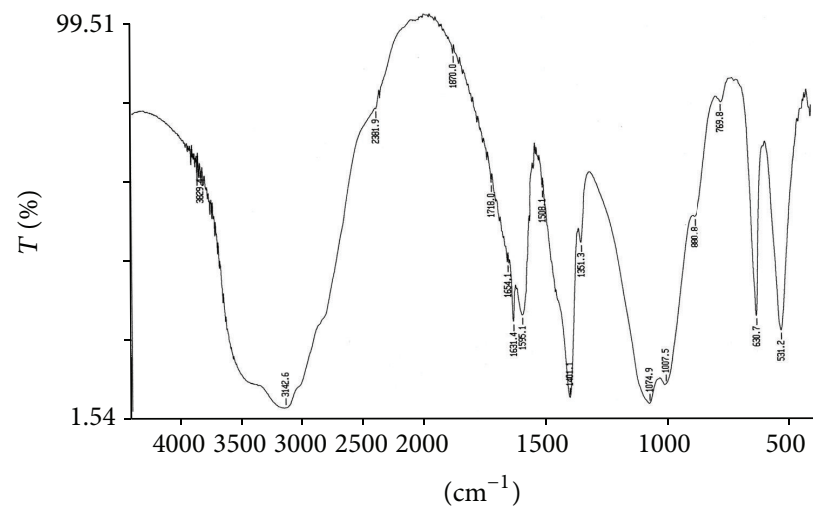

(b)

FIGURE 6: FT-IR spectra depicting the various functional groups present in (a) yttrium phosphate $\left(\mathrm{YPO}_{4}\right)$; (b) dysprosium doped yttrium phosphate $\left(\mathrm{Dy}: \mathrm{YPO}_{4}\right)$. 


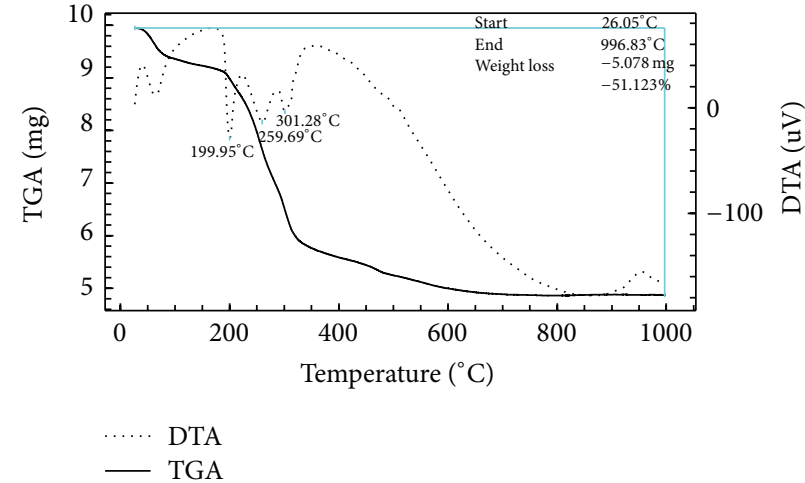

(a)

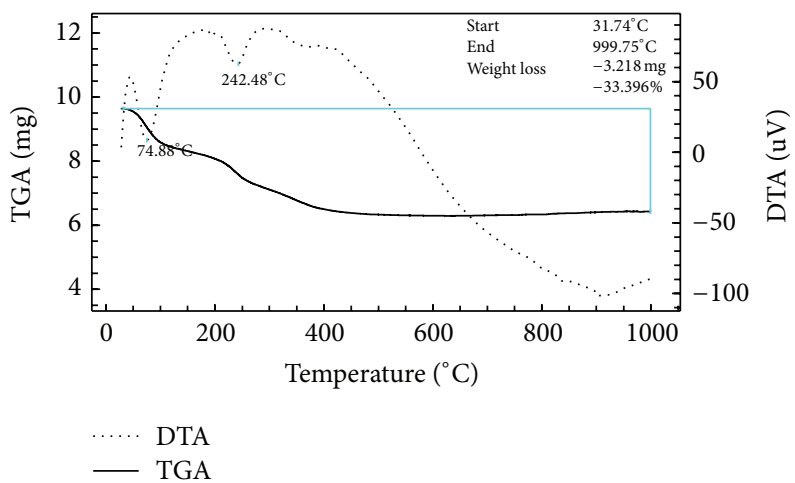

(b)

FIGURE 7: (a) Thermograph depicting simultaneous recording of TGA and DTA curves which clearly shows that pure $\mathrm{YPO}_{4} \mathrm{crystal}$ is thermally unstable as the temperature increases from room temperature to higher values. (b) Thermograph of Dy:YPO ${ }_{4}$ depicting the TGA and DTA curves shows that it is thermally more stable as compared to the pure crystals of $\mathrm{YPO}_{4}$.

the table theoretical values of the lighter element $(\mathrm{H})$ based on the formula have been given, and it is found that the experimental and theoretical values are in close agreement with each other within the experimental error. The presence of $\mathrm{H}_{2} \mathrm{O}$ molecules in $\mathrm{YP}$ and DyYP was further confirmed by FTIR and thermoanalytical analysis.

3.5. Fourier Transform Infrared Spectroscopy (FT-IR). The infrared spectrum is formed as a consequence of the absorption of electromagnetic radiation at frequencies that correlate with the vibration of specific sets of chemical bonds from a molecule. Thus, the vibrational spectrum of a molecule is considered to be a unique physical property and is characteristic of the molecule. Figures 6(a) and 6(b) shows the FTIR spectrum for YP and DyYP, respectively. On analyzing the spectrum, it was observed that grown crystals show the presence of water molecules, orthophosphate group and metallic ions group. For the water vibration in addition to the wide bands associated with different types of $\mathrm{OH}$ groups extending from 3829.4 to 2424.2 in case of YP and from 3829.4 to 2381.9 in case of DyYP the presence of two bands at 1631.6, 1596 in YP and 1631.4, 1595.1 in DyYP is indicative of the characteristics of coordinated water molecule [19], that is, the hydrated water molecule in the as-synthesized sample are chemically bonded to the rare earth ions $[28,29]$. The bands from orthophosphate functional group were observed at $1074.9,1070.9,1007.5$, and $933.6 \mathrm{~cm}^{-1}$ in both the cases with the difference that for doped yttrium phosphate the values of transmittance decreases which can be attributed to the doping effect $[30,31]$. The band around this wave number was attributed to the symmetric stretching mode $\left(v_{4}\right)$ and asymmetric stretching mode $\left(\nu_{3}\right)$ of $\mathrm{PO}_{4}$ tetrahedron $[32,33]$. The bands at $630.7,627.2,542.6$, and $531.2 \mathrm{~cm}^{-1}$ show the presence of metallic ions. Tables 2(a) and 2(b) give complete information about the type of functional groups present in YP and DyYP along with their frequency bands and transmittance percentage.

3.6. Thermal Decomposition. Thermogravimetric analysis is a technique to assess the stability of various substances.
TABLE 1: Experimental and theoretical calculated composition obtained from energy dispersive X-ray analysis (EDAX) of various constituent elements present in the following cases.

(a) Yttrium phosphate $\left(\mathrm{YPO}_{4}\right)$

\begin{tabular}{lcccc}
\hline \multirow{2}{*}{ Element } & \multicolumn{2}{c}{ Experimental values } & \multicolumn{2}{c}{ Theoretical values } \\
& $\mathrm{Wt} \%$ & At\% & $\mathrm{Wt} \%$ & $\mathrm{At} \%$ \\
\hline Oxygen & 32.92 & 56.34 & 30.8 & 55.42 \\
Phosphorous & 11.08 & 12.03 & 11.95 & 11.08 \\
Yttrium & 33.15 & 09.23 & 34.31 & 11.08 \\
Hydrogen & - & - & 22.94 & 22.42 \\
\hline
\end{tabular}

(b) Dysprosium doped yttrium phosphate $\left(\mathrm{Dy}: \mathrm{YPO}_{4}\right)$

\begin{tabular}{lcccc}
\hline \multirow{2}{*}{ Element } & \multicolumn{2}{c}{ Experimental values } & \multicolumn{2}{c}{ Theoretical values } \\
& Wt\% & At\% & Wt\% & At\% \\
\hline Oxygen & 40.12 & 68.07 & 42.15 & 70.89 \\
Phosphorous & 11.29 & 12.19 & 13.60 & 11.82 \\
Dysprosium & 01.13 & 00.68 & 01.43 & 00.24 \\
Yttrium & 38.40 & 10.10 & 38.26 & 11.58 \\
Hydrogen & - & - & 4.56 & 5.47 \\
\hline
\end{tabular}

Figures 7(a) and 7(b) show the simultaneously recorded thermogravimetric analysis (TGA) and differential thermogravimetric analysis (DTA) curve for YP and DyYP crystal. Thermograms were first analyzed to obtain information about the percentage mass loss at different temperatures and hence about the thermal stability and kinetics of dissociation of crystals. YP and DyYP when heated at a uniform rate of $10^{\circ} \mathrm{C} / \mathrm{min}$, mass was found to lose continuously, as a function of temperature applied. For YP starts to decompose at $39^{\circ} \mathrm{C}$, and the decomposition went up to $706^{\circ} \mathrm{C}$ in three different stages. However, in case of DyYP the decomposition starts at $43^{\circ} \mathrm{C}$, and the thermal stability was acquired by the material at $519^{\circ} \mathrm{C}$ in two different stages. During these temperature ranges, the mass loss was $50.9 \%$ and $32.6 \%$ for YP and DyYP respectively. Therefore, the mechanism involved in the decomposition of the constituent material is different for pure 
TABLE 2: Presence of various functional groups along with their frequency bands and transmittance percentage for the following.

(a) Yttrium phosphate $\left(\mathrm{YPO}_{4}\right)$

\begin{tabular}{lcc}
\hline $\begin{array}{l}\text { Assignments of } \\
\text { bands/peaks }\end{array}$ & IR bands $\left(\mathrm{cm}^{-1}\right)$ & $\begin{array}{c}\text { Transmittance } \\
\text { percentage (\%) }\end{array}$ \\
\hline \multirow{2}{*}{$\mathrm{PO}_{4}$} & 1070.9 & $10 \%$ \\
& 1007.5 & $18 \%$ \\
\hline \multirow{2}{*}{$\mathrm{OH}$} & 933.6 & $20 \%$ \\
\hline \multirow{2}{*}{ Metallic ion } & 3829.4 & $60 \%$ \\
& 3142.6 & $2 \%$ \\
\hline
\end{tabular}

(b) Dysprosium doped yttrium phosphate (Dy: $\left.\mathrm{YPO}_{4}\right)$

\begin{tabular}{lcc}
\hline $\begin{array}{l}\text { Assignments of } \\
\text { bands/peaks }\end{array}$ & IR bands $\left(\mathrm{cm}^{-1}\right)$ & $\begin{array}{c}\text { Transmittance } \\
\text { percentage (\%) }\end{array}$ \\
\hline $\mathrm{PO}_{4}$ & 1074.9 & $5 \%$ \\
\hline $\mathrm{OH}$ & 1007.5 & $10 \%$ \\
\hline \multirow{2}{*}{ Metallic ion } & 3829.4 & $60 \%$ \\
& 3142.6 & $5 \%$ \\
\hline
\end{tabular}

and doped one. Our group has earlier reported $[34,35]$ the growth and thermal kinetics of pure and cadmium-doped barium/calcium phosphate single crystal.

From Figure 7(a), YP system is thermally stable up to a temperature of $39^{\circ} \mathrm{C}$ and thereafter starts decomposing. The whole process of decomposition completes in three steps. The first stage of decomposition begins from $39^{\circ} \mathrm{C}$ and continues up to a temperature of $176^{\circ} \mathrm{C}$ resulting in a weight loss of $7.9 \%$ of the total weight. First step of decomposition involves conversion of hydrated YP crystal into anhydrous in nature. The second stage of decomposition starts from $176^{\circ} \mathrm{C}$ and ends at a temperature of $437^{\circ} \mathrm{C}$ leading to weight loss of $37 \%$. This weight loss in the second stage of decomposition corresponds to the conversion of anhydrous $\mathrm{YPO}_{4}$ to $\mathrm{Y}_{2} \mathrm{O}_{3}$. The third stage of decomposition starts from $437^{\circ} \mathrm{C}$ and goes up to $706^{\circ} \mathrm{C}$ resulting in weight loss of $6 \%$ during which the intermediate product $\mathrm{Y}_{2} \mathrm{O}_{3}$ decomposes to form $\mathrm{YO}$ with the release of half a molecule of oxygen as the final product. This type of fractional release of oxygen molecule has also been reported earlier by Brown [36] during the thermal decomposition of inorganic solids. Table 3(a) gives the compiled summary of the decomposition process of $\mathrm{YPO}_{4} \cdot \mathrm{H}_{2} \mathrm{O}$. It can be seen that the calculated weight loss is in close proximity with the observed values. Based on these thermal analyses, we confirm that the grown crystal is having a composition of $\mathrm{YPO}_{4} \cdot \mathrm{H}_{2} \mathrm{O}$.

From the thermogram of DyYP (Figure 7(b)), it is clear that the doped crystal is thermally stable up to temperature of $43^{\circ} \mathrm{C}$, which means that doped crystal is more stable than pure one. In case of DyYP, the decomposition takes place in two steps. In the first step from 43 to $176^{\circ} \mathrm{C}$, two water molecules attached to the doped system get decomposed. In the second stage of the decomposition, doped orthophosphate reduces to pyrophosphate with the release of phosphorous oxide and oxygen. Table $3(\mathrm{~b})$ gives detailed summary of the decomposition of $\mathrm{Dy}_{0.02} \mathrm{Y}_{0.98} \mathrm{PO}_{4} \cdot 2 \mathrm{H}_{2} \mathrm{O}$ along with observed as well as calculated weight losses. In this case, the calculated and observed weight losses are in close agreement with each other. It is worth mentioning here that the temperature for the formation of stable product after decomposition in case of pure one is $706^{\circ} \mathrm{C}$, whereas in case of doped one the stable product is formed at a temperature of $519^{\circ} \mathrm{C}$. This means that the temperature for the formation of end product decreases with dysprosium substitution.

The thermal decomposition of $\mathrm{YPO}_{4}$ into yttrium oxide through different stages has been accomplished with the release of $\mathrm{H}_{2} \mathrm{O}, \mathrm{P}_{2} \mathrm{O}_{5}$ and $\mathrm{O}_{2}$, whereas for doped Dy: $\mathrm{YPO}_{4}$ the decomposition was accompanied by the release of $\mathrm{H}_{2} \mathrm{O}, \mathrm{PO}_{3}$, and $\mathrm{O}_{2}$. Corresponding to each stage of decomposition, there are endothermic and exothermic peaks in the DTA curve. As seen from DTA curve in case of YP (Figure 7(a)) and DyYP (Figure 7(b)) there is well-marked endothermic and exothermic peak corresponding to each stage of decomposition. Since peaks in DTA curve correspond to weight loss in TGA curve, thereby suggesting that some changes takes place in the material because of the weight loss in the material.

From the thermal analysis of the system, we can therefore confirm that product formed in the pure form, that is, yttrium phosphate is associated with one water molecules having composition $\mathrm{YPO}_{4} \cdot \mathrm{H}_{2} \mathrm{O}$, whereas the doped one that is, dysprosium doped yttrium phosphate, is associated with two water molecules having composition $\mathrm{Dy}_{0.02} \mathrm{Y}_{0.98} \mathrm{PO}_{4} \cdot 2 \mathrm{H}_{2} \mathrm{O}$. These compositions were further supported by other analyses like energy dispersive X-ray analysis (EDAX) and Fourier transform infrared (FTIR) spectroscopy.

\section{Conclusions}

From the research work carried out over the synthesis and characterization of the pure and dysprosium doped yttrium phosphate, the following conclusions can be drawn.

(1) Pure yttrium phosphate with composition $\mathrm{YPO}_{4} \cdot \mathrm{H}_{2} \mathrm{O}$ is obtained in the form of platelet like crystals, whereas the dysprosium doped yttrium phosphate having composition $\mathrm{Dy}_{0.02} \mathrm{Y}_{0.98} \mathrm{PO}_{4} \cdot 2 \mathrm{H}_{2} \mathrm{O}$ is obtained in the form of floral growth on the condensed gel.

(2) Yttrium phosphate and dysprosium doped yttrium phosphate belong to tetragonal system. The lattice parameters obtained in case of YP are $a=b=$ $6.8832 \AA, c=6.0208 \AA$. Similarly the lattice parameters in case of doped one, that is, DyYP, come out to be $a=b=6.9987 \AA, c=6.0142 \AA$. Thus, the crystal structure of yttrium phosphate remains unaffected by modification of its composition by dysprosium.

(3) Scanning electron microscopy (SEM) studies give a clear picture about the morphology of the grown crystals. The qualitative and quantitative elemental analyses employing EDAX technique confirm the 
TABLE 3: Results of thermal decomposition for different temperature ranges with observed and calculated weight loss in the following cases.

(a) Yttrium phosphate (YP)

\begin{tabular}{lcccc}
\hline Stage & Temperature $\left({ }^{\circ} \mathrm{C}\right)$ & Decomposition steps & \multicolumn{2}{c}{ Weight loss (\%) } \\
& & & Observed & 7.9 \\
First & $39-176$ & $\mathrm{YPO}_{4} \cdot \mathrm{H}_{2} \mathrm{O} \rightarrow \mathrm{YPO}_{4}+\mathrm{H}_{2} \mathrm{O}$ & 37 & 8.9 \\
Second & $176-437$ & $2\left[\mathrm{YPO}_{4}\right] \rightarrow \mathrm{Y}_{2} \mathrm{O}_{3}+\mathrm{P}_{2} \mathrm{O}_{5}(\mathrm{~g})$ & 6.7 \\
Third & $437-706$ & $\mathrm{Y}_{2} \mathrm{O}_{3} \rightarrow \mathrm{YO}+0.5 \mathrm{O}_{2}(\mathrm{~g})$ & 7 \\
\hline
\end{tabular}

(b) Dysprosium doped yttrium phosphate (DyYP)

\begin{tabular}{lcccc}
\hline Stage & \multirow{2}{*}{ Temperature $\left({ }^{\circ} \mathrm{C}\right)$} & \multirow{2}{*}{ Decomposition steps } & \multicolumn{2}{c}{ Weight loss (\%) } \\
Observed & Calculated \\
\hline First & $43-176$ & $\mathrm{Dy}_{0.02} \mathrm{Y}_{0.98} \mathrm{PO}_{4} \cdot 2 \mathrm{H}_{2} \mathrm{O} \rightarrow \mathrm{Dy}_{0.02} \mathrm{Y}_{0.98} \mathrm{PO}_{4}+2 \mathrm{H}_{2} \mathrm{O}$ & 13.65 & 16.28 \\
Second & $176-519$ & $3\left[\mathrm{Dy}_{0.02} \mathrm{Y}_{0.98} \mathrm{PO}_{4}\right] \rightarrow\left(\mathrm{Dy}_{0.02} \mathrm{Y}_{0.98}\right)_{2} \mathrm{P}_{2} \mathrm{O}_{7}+\mathrm{PO}_{3}(\mathrm{~g})+\mathrm{O}_{2}$ & 19.04 & 19.95 \\
\hline
\end{tabular}

presence of major elements in the grown material. The stoichiometric composition of the grown system as established by EDAX technique is $\mathrm{YPO}_{4} \cdot \mathrm{H}_{2} \mathrm{O}$ and $\mathrm{Dy}_{0.02} \mathrm{Y}_{0.98} \mathrm{PO}_{4} \cdot 2 \mathrm{H}_{2} \mathrm{O}$.

(4) Fourier transformed infrared studies on YP and DyYP confirm the presence of water molecules, orthophosphate functional group and metallic ion group. The frequency bands within the range of 3829.4 to $2424.2 \mathrm{~cm}^{-1}$ are attributed to the presence of water molecules. The effect of doping can be seen clearly in FTIR spectrum where the transmittance percentage decreases in case of DyYP.

(5) The thermal studies carried out on YP and DyYP reveal that pure yttrium phosphate is less stable as compared to doped yttrium phosphate. $\mathrm{YPO}_{4}$ starts to decompose early and becomes stable at a later stage in comparison to its doped counterpart.

(6) The thermal decomposition of YP into the final stable product of yttrium monoxide underwent three different stages with the release of $\mathrm{H}_{2} \mathrm{O}, \mathrm{P}_{2} \mathrm{O}_{5}$, and $\mathrm{O}_{2}$ whereas for DyYP the decomposition was accompanied by the release of $\mathrm{H}_{2} \mathrm{O}, \mathrm{PO}_{3}$, and $\mathrm{O}_{2}$, and a final product of doped yttrium pyrophosphate was obtained.

\section{References}

[1] Z. A. Kazei, N. P. Kolmakova, and O. A. Shishkina, "Magnetoelastic contribution to thermal expansion of rare-earth zircons," Physics B, vol. 245, no. 2, pp. 164-172, 1998.

[2] V. Mehta, G. Aka, A. L. Dawarb, and A. Mansingh, "Optical properties and spectroscopic parameters of $\mathrm{Nd}^{3+}$-doped phosphate and borate glasses," Optical Materials, vol. 12, pp. 53-63, 1999.

[3] K. Riwotzki, H. Meyssamy, A. Kornowski, and M. Haase, "Liquid-phase synthesis of doped nanoparticles: colloids of luminescing $\mathrm{LaPO}_{4}: \mathrm{Eu}$ and $\mathrm{CePO}_{4}: \mathrm{Tb}$ particles with a narrow particle size distribution," Journal of Physical Chemistry B, vol. 104, no. 13, pp. 2824-2828, 2000.

[4] N. Imanaka, T. Masui, H. Hirai, and G. Y. Adachi, "Amorphous cerium-titanium solid solution phosphate as a novel family of band gap tunable sunscreen materials," Chemistry of Materials, vol. 15, no. 12, pp. 2289-2291, 2003.

[5] W. W. Moses, M. J. Weber, S. E. Derenzno, D. Perry, P. Berdahl, and L. A. Boatnor, "Prospects for dense, infrared emitting scintillators," IEEE Transactions on Nuclear Science, vol. 45, pp. 462-466, 1998.

[6] A. J. Wojtowicz, D. Wisniewski, A. Lempicki, and L. A. Boatner, "Scintillation mechanisms in rare earth orthophosphates," Radiation Effects and Defects in Solids, vol. 135, no. 1, pp. 305310, 1995.

[7] A. Lempicki, E. Berman, A. J. Wojtowicz, M. Balcerzyk, and L. A. Boatner, "Cerium-doped orthophosphates: new promising scintillators," IEEE Transactions on Nuclear Science, vol. 40, no. 4, pp. 384-387, 1993.

[8] S. W. Allison, L. A. Boatner, and G. T. Gillies, "Characterization of high-temperature thermographic phosphors: spectral properties of $\mathrm{LuPO}_{4}: \mathrm{Dy}(1 \%), \mathrm{Eu}(2 \%)$," Applied Optics, vol. 25, pp. 5624-5627, 1995.

[9] E. Jarosewich and L. A. Boatner, "Rare-earth element reference samples for electron microprobe analysis," Geostandards Newsletter, vol. 15, pp. 397-399, 1991.

[10] J. Dhanaraj, R. Jagannathan, T. R. N. Kutty, and C. H. Lu, "Photoluminescence characteristics of $\mathrm{Y}_{2} \mathrm{O}_{3}: \mathrm{Eu}^{3+}$ nanophosphors prepared using sol-gel thermolysis," Journal of Physical Chemistry B, vol. 105, no. 45, pp. 11098-11105, 2001.

[11] Z. Wei, L. Sun, C. Liao, C. Yan, and S. Huang, "Fluorescence intensity and color purity improvement in nanosized $\mathrm{YBO}_{3}: \mathrm{Eu}$," Applied Physics Letters, vol. 80, no. 8, pp. 1447-1449, 2002.

[12] R. S. Meltzer, S. P. Feofilov, B. Tissue, and H. B. Yuan, "Dependence of fluorescence lifetimes of $\mathrm{Y}_{2} \mathrm{O}_{3}: \mathrm{Eu}^{3+}$ nanoparticles on the surrounding medium," Physical Review B, vol. 60, no. 20, pp. R14012-R14015, 1999.

[13] H. Hirai, T. Masui, N. Imanaka, and G. Y. Adachi, "Characterization and thermal behavior of amorphous rare earth phosphates," Journal of Alloys and Compounds, vol. 374, no. 12, pp. 84-88, 2004.

[14] Y. Guo, P. Woznicki, A. Barkatt, E. E. Saad, and I. G. Talmy, "Solgel synthesis of microcrystalline rare earth orthophosphates," Journal of Materials Research, vol. 11, no. 3, pp. 639-649, 1996.

[15] D. Bregiroux, S. Lucas, E. Champion, F. Audubert, and D. Bernache-Assollant, "Sintering and microstructure of rare earth phosphate ceramics $R E \mathrm{PO}_{4}$ with $R E=\mathrm{La}$, Ce or Y," Journal of the European Ceramic Society, vol. 26, no. 3, pp. 279-287, 2006. 
[16] J. Zhu, W. D. Cheng, D. S. Wu et al., "Crystal and band structures, and optical characterizations of sodium rare earth phosphates $\mathrm{NaLnP}_{2} 2 \mathrm{O}_{7}$ and $\mathrm{NaLn}\left(\mathrm{PO}_{3}\right)_{4}(\mathrm{Ln}=\mathrm{Ce}, \mathrm{Eu})$," Journal of Alloys and Compounds, vol. 454, no. 1-2, pp. 419-426, 2008.

[17] H. Lai, A. Bao, Y. Yang et al., "UV luminescence property of $\mathrm{YPO}_{4}: \mathrm{RE}\left(\mathrm{RE}=\mathrm{Ce}^{3+}, \mathrm{Tb}^{3+}\right)$," Journal of Physical Chemistry $C$, vol. 112, no. 1, pp. 282-286, 2008.

[18] J. M. Nedelec, D. Avignant, and R. Mahiou, "Soft chemistry routes to $\mathrm{YPO}_{4}$-based phosphors: dependence of textural and optical properties on synthesis pathways," Chemistry of Materials, vol. 14, no. 2, pp. 651-655, 2002.

[19] S. Lucas, E. Champion, D. Bernache-Assollant, and G. Leroy, "Rare earth phosphate powders $R e \mathrm{PO}_{4} \cdot n \mathrm{H}_{2} \mathrm{O}(R e=\mathrm{La}, \mathrm{Ce}$ or Y) II. Thermal behavior," Journal of Solid State Chemistry, vol. 177, no. 4-5, pp. 1312-1320, 2004.

[20] R. S. Fugelson, "Synthesis and single-crystal growth of rareearth orthophosphates," Journal of the American Ceramic Society, vol. 47, pp. 257-258, 1964.

[21] N. N. Chudinova, L. P. Shklover, and G. M. Balagina, "Reactions of lanthanum oxide with phosphoric acids at $100-500^{\circ} \mathrm{C}$," Inorganic Materials, vol. 11, pp. 590-593, 1975.

[22] N. Arul-Dhas and K. C. Patel, "Synthesis of $\mathrm{AlPO}_{4}, \mathrm{LaPO}_{4}$ and $\mathrm{KTiOPO}_{4}$ by flash combustion," Journal of Alloys and Compounds, vol. 202, pp. 137-141, 1993.

[23] H. Onoda, H. Nariani, H. Maki, and I. Motooka, "Mechanochemical effects on synthesis of Rhabdophane-type neodymium and cerium phosphates," Materials Chemistry and Physics, vol. 78, pp. 400-404, 2002.

[24] O. Terra, N. Dacheux, R. Podar, and N. Clavier, "Preparation and characterization of lanthanum-gadolinium monazites as ceramics for radioactive waste storage," New Journal of Chemistry, vol. 27, pp. 957-967, 2003.

[25] S. V. Ushakov, K. B. Helean, A. Navrotsky, and L. A. Boatner, "Thermochemistry of rare-earth orthophosphates," Journal of Materials Research, vol. 16, no. 9, pp. 2623-2633, 2001.

[26] Y. Endo and I. Sunagawa, "Positive and negative striations in pyrite," American Mineralogist, vol. 58, pp. 930-935, 1973.

[27] B. Cockayne and M. P. Gates, "Growth striations in vertically pulled oxide and fluoride single crystals," Journal of Materials Science, vol. 2, pp. 118-123, 1967.

[28] W. Di, X. X. Zhao, S. Lu, X. Wang, and H. Zhao, “Thermal and photoluminescence properties of hydrated $\mathrm{YPO}_{4}: \mathrm{Eu}^{3+}$ nanowires," Journal of Solid State Chemistry, vol. 180, pp. 24782484, 2007.

[29] L. Qiong, S. Yiguo, Y. H. Sheng, and H. Wei, "YPO ${ }_{4}$ nanocrystals: preparation and size-induced lattice symmetry enhancement," Journal of Rare Earths, vol. 26, no. 4, pp. 495-500, 2008.

[30] S. Lucas, E. Champion, C. Penot, G. Leroy, and D. BernacheAssollant, "Synthesis and characterization of rare earth phosphate powders," Key Engineering Materials, vol. 206-213, pp. 4750, 2001.

[31] A. Hezel and S. D. Ross, "Forbidden transitions in the infrared spectra of tetrahedral anions-III. Spectra-structure correlations in perchlorates, sulphates and phosphates of the formula $\mathrm{MXO}_{4}$," Spectrochimica Acta, vol. 22, pp. 1949-1961, 1966.

[32] D. K. Breitinger, G. Brehm, J. Mohr et al., "Vibrational spectra of synthetic crandallite-type minerals-optical and inelastic neutron scattering spectra," Journal of Raman Spectroscopy, vol. 37, no. 1-3, pp. 208-216, 2006.
[33] M. J. Bushiri, R. S. Jayasree, M. Fakhfakh, and V. U. Nayar, "Raman and infrared spectral analysis of thallium niobyl phosphates: $\mathrm{Tl}_{2} \mathrm{NbO}_{2} \mathrm{PO}_{4}, \mathrm{Tl}_{3} \mathrm{NaNb}_{4} \mathrm{O}_{9}\left(\mathrm{PO}_{4}\right)_{2}$ and $\mathrm{TlNbOP}_{2} \mathrm{O}_{7}$," Materials Chemistry and Physics, vol. 73, pp. 179-185, 2002.

[34] S. Suri, K. K. Bamzai, and V. Singh, "Growth and thermal kinetics of pure and cadmium doped barium phosphate single crystal," Journal of Thermal Analysis and Calorimetry, vol. 105, no. 1, pp. 229-238, 2011.

[35] K. K. Bamzai, S. Suri, and V. Singh, "Synthesis, characterization, thermal and dielectric properties of pure and cadmium doped calcium hydrogen phosphate," Materials Chemistry and Physics, vol. 135, pp. 158-167, 2012.

[36] M. E. Brown, "Quantitative thermoanalytical studies of the kinetics and mechanisms of the thermal decomposition of inorganic solids," Thermochimica Acta, vol. 110, pp. 153-158, 1987. 

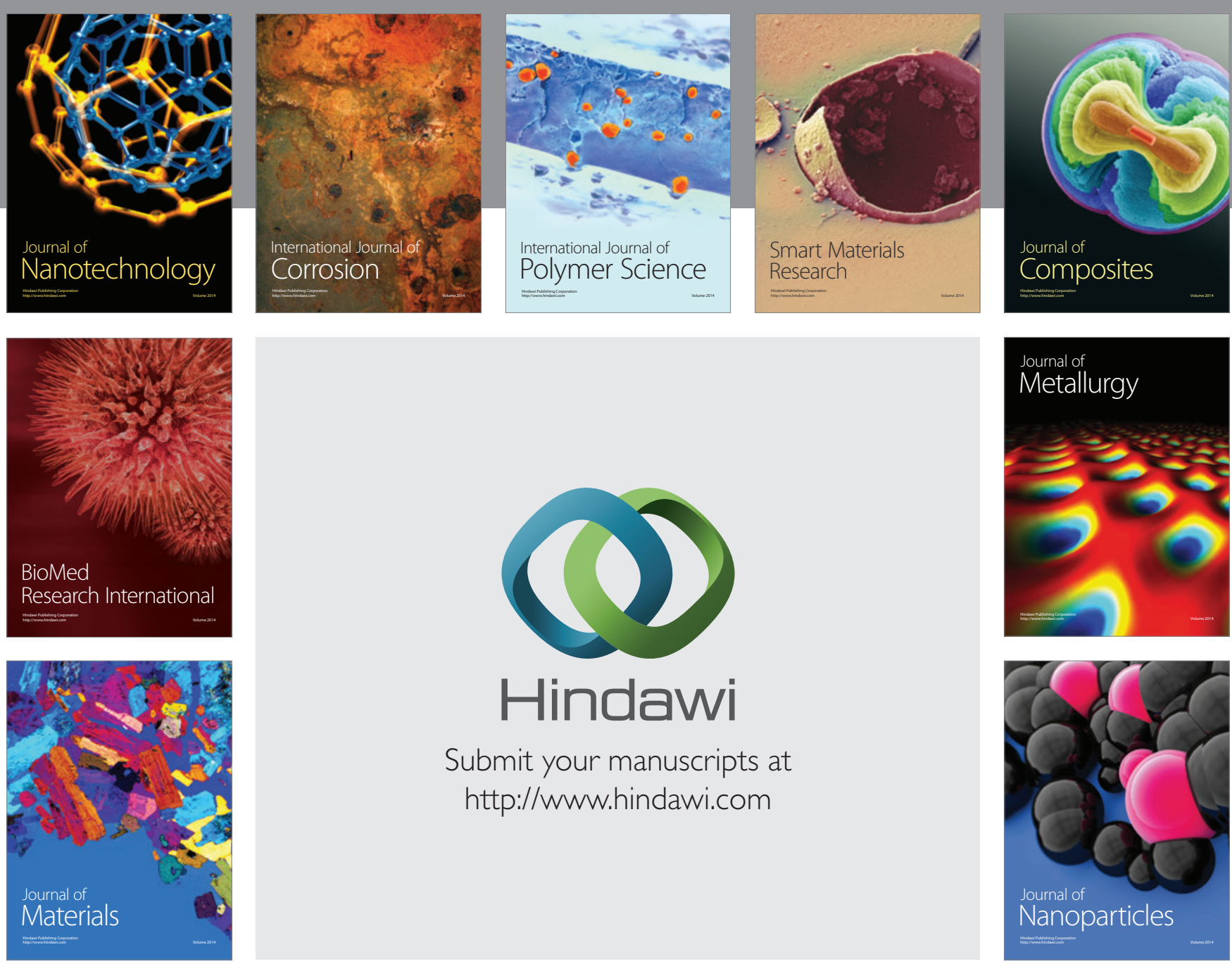

Submit your manuscripts at http://www.hindawi.com
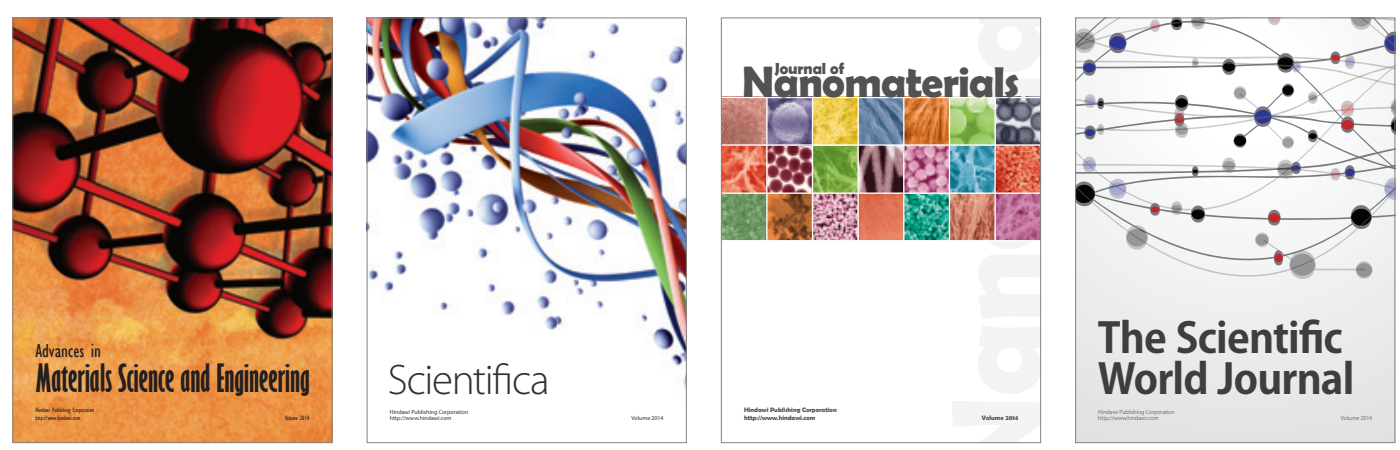

\section{The Scientific World Journal}
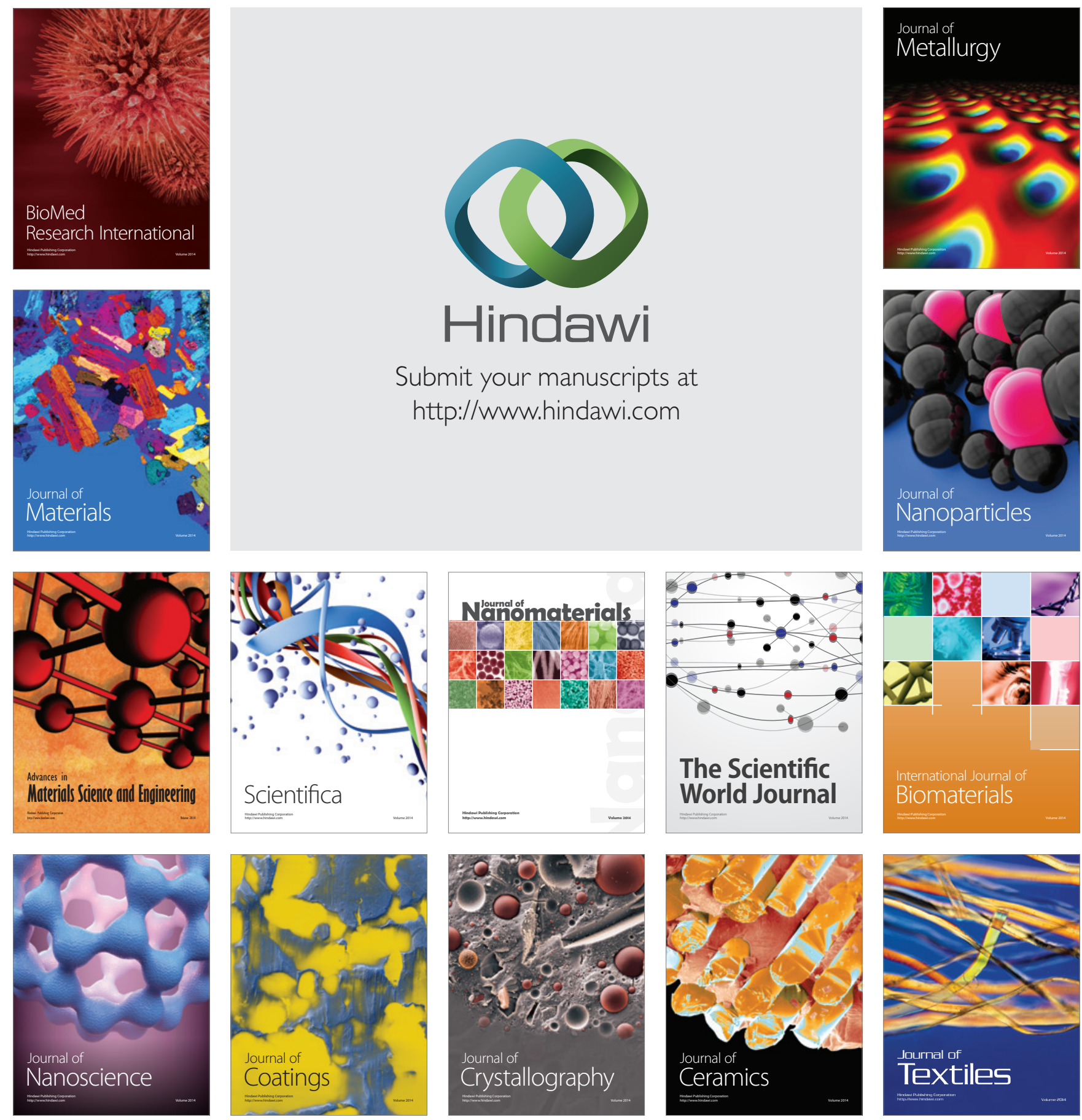